\title{
Temporal changes in biotypes of Haemophilus influenzae isolated from patients with cystic fibrosis
}

\author{
K. C. WATSON, E. J. C. KERR and MAUREEN BAILLIE
}

Central Microbiological Laboratories, Western General Hospital, Crewe Road, Edinburgh EH4 2XU, Scotland

\begin{abstract}
Summary. Isolates of Haemophilus influenzae obtained sequentially over a period of 2 years from 62 patients with cystic fibrosis were biotyped. Rapid changes were seen from month to month in biotypes isolated from the respiratory tract and only a few of the patients harboured the same biotype for several months. Up to four biotypes were present simultaneously, whereas even two different biotypes were found in only one of a series of 148 patients with respiratory infections but not cystic fibrosis. Colony morphology was no guide to biotype, since the same biotype may show different colony appearances on the same plate and different biotypes may show identical colony forms.
\end{abstract}

\section{Introduction}

The biotyping scheme for Haemophilus influenzae introduced by Kilian (1976) has been studied in relation to serotypes, sources of isolation, antibiotic sensitivity and the geographical distribution of strains. The method has epidemiological implications and we have already reported on the distribution of biotypes of isolates from patients with cystic fibrosis in comparison with normal subjects and patients with respiratory infection but without cystic fibrosis (Watson et al., 1985).

Determination of the biotype of a single isolate of $H$. influenzae clearly has certain limitations, particularly with isolates from the respiratory tract where this organism forms part of the normal flora. Patients with cystic fibrosis, however, offer particular opportunities for sequential follow-up. We report changes in biotype in a group followed for 2 years with a view to answering two questions. First, does one biotype colonise the respiratory tract for a long period or do biotypes change frequently, and second, are patients colonised with only one biotype at any one time or may several biotypes co-exist?

\section{Materials and methods}

\section{Patients}

The cystic fibrosis group comprised 62 patients from whom sputum samples or cough swabs were obtained over the 2 years from March 1984 to March 1986. We aimed to obtain monthly specimens but this was not

Received 24 Dec. 1986; revised version accepted 30 Sep. 1987. always possible, so that only a smaller number was available for detailed analysis.

Two other groups included 148 patients without cystic fibrosis who had respiratory infections, and 74 patients free of respiratory infection but from whom $H$. influenzae was isolated from other sites such as the throat (the majority), blood, urine, cerebrospinal fluid and conjunctivae. Only one specimen was available from each patient in these two groups and no sequential samples could be obtained.

\section{Bacteria}

Gram-negative organisms corresponding to the description of the genus Haemophilus were isolated on heated-blood-agar plates supplemented with bacitracin $10 \mathrm{IU} / \mathrm{ml}$, incubated overnight at $37^{\circ} \mathrm{C}$ in $\mathrm{CO}_{2} 10 \%$. Single colonies were subcultured to heated blood agar and incubated overnight before testing for ability to convert $\delta$-amino-laevulinic acid to porphyrins. ONPG negative, porphyrin negative, $\mathrm{XV}$ factor dependent strains were identified as $H$. influenzae.

Colony morphological appearances varied. On some plates a single, uniform morphological type was apparent; on others two or more different forms were noted. In every case, three colonies of each type were picked off for biotyping.

\section{Biotypes}

In earlier studies, strains were biotyped according to API recommendations based on the technique described by Mehtar and Afshar (1983) in which a single colony is emulsified in $3 \mathrm{ml}$ of deionised water $(p \mathrm{H} \mathrm{7 \cdot 0)}$ containing one standard XV disc. Subsequently, we reported that this procedure was unsatisfactory because of the small 
inoculum size (Watson et al., 1986), so a heavy inoculum of $1.25 \times 10^{8} \mathrm{cfu} / \mathrm{ml}$ suspended in sterile distilled water $(p \mathrm{H} \mathrm{7.0)}$ was always used in this study. API-10S strips were inoculated in the usual way and replicate tests were performed in $3^{\prime \prime} \times \frac{1^{\prime \prime}}{2}$ tubes, each containing $0.25-\mathrm{ml}$ volumes of double-strength media. Modified Christensen's medium was used to detect urease and modified Falkow's medium for ornithine decarboxylase. Indole formation was determined in double strength peptone water with Kovacs's reagent. API-10S strips and tube methods gave identical results when used with a heavy inoculum.

\section{Results}

Biotype distribution for 1984 and 1985 in the cystic fibrosis group is shown in table $I$ and compared with the totals for the other two groups.

Table I. Distribution of biotypes of $H$. influenzae from patients with (a) cystic fibrosis, (b) respiratory infections but not cystic fibrosis, and (c) isolates from patients with no respiratory infection

\begin{tabular}{l|cccc}
\hline & \multicolumn{3}{|c}{ Number $(\%)$ of strains isolated from patients with } \\
\cline { 2 - 5 } Biotype & $\begin{array}{c}\text { Cystic } \\
\text { fbrosis } \\
(1984)\end{array}$ & $\begin{array}{c}\text { Cystic } \\
\text { fibrosis } \\
(1985)\end{array}$ & $\begin{array}{c}\text { Respiratory } \\
\text { infection }\end{array}$ & $\begin{array}{c}\text { No } \\
\text { respiratory } \\
\text { infection }\end{array}$ \\
\hline I & $31(22 \cdot 3)$ & $30(18 \cdot 9)$ & $28(18 \cdot 7)$ & $16(21 \cdot 6)$ \\
II & $39(28)$ & $29(18 \cdot 3)$ & $55(36 \cdot 9)$ & $28(37 \cdot 8)$ \\
III & $22(15 \cdot 8)$ & $49(31)$ & $29(19 \cdot 4)$ & $16(21 \cdot 6)$ \\
IV & $17(12 \cdot 2)$ & $9(5 \cdot 6)$ & $10(6 \cdot 7)$ & $3(4)$ \\
V & $18(12 \cdot 9)$ & $21(13 \cdot 2)$ & $19(12 \cdot 7)$ & $9(12 \cdot 1)$ \\
VI & $4(2 \cdot 8)$ & $7(4 \cdot 4)$ & $4(2 \cdot 6)$ & $2(2 \cdot 7)$ \\
VII & $2(1 \cdot 4)$ & $4(2 \cdot 5)$ & $4(2 \cdot 6)$ & $0(0)$ \\
VIII & $6(4 \cdot 3)$ & $9(5 \cdot 6)$ & $0(0)$ & $0(0)$ \\
Total & 139 & 158 & 149 & 74 \\
\hline
\end{tabular}

Biotypes I-VI correspond to the Kilian (1976) classification. Biotype-VII strains are indole-positive, ornithine decarboxylase-negative and ureasenegative as described by Gratten (1983). Biotype VIII strains gave negative results in all three tests as described by Sottnek and Albritton (1984).

Table II shows in greater detail the comparative distribution of biotypes in the cystic fibrosis group for three 3-month periods of 1984 and the corresponding months of 1985 . The intervening 3-month period has been omitted for the sake of comparing one year with the following.

In the cystic fibrosis group, the proportion of biotype-III strains rose from $15.8 \%$ of all isolates in 1984 to $31 \%$ in 1985 , accounting for $46.5 \%$ of strains in April-June 1985 but only $19.7 \%$ by the end of that year, a figure similar to that recorded with the other two study groups. There was a higher incidence of biotype-II strains in the respiratory illness and non-respiratory groups than in the cystic fibrosis group, confirming our previous experience (Watson et al., 1985). During the first 3 months of 1986 , biotype-II isolates rose to $50 \%$ for the respiratory illness and non-respiratory groups compared with $30 \%$ in the cystic fibrosis patients. Biotype-I strains occurred with almost equal frequency in all groups. Biotype-IV strains were commoner in the cystic fibrosis group in 1984 but present in similar numbers in all three groups in 1985. Biotype V strains were also distributed similarly in all three groups, although biotype $\mathrm{V}$ accounted for $22.5 \%$ of strains in the cystic fibrosis group in the last 3 months of 1985 but only $4.6 \%$ in April-June of that year. Fluctuation in biotypes between April 1984 and February 1986 is shown in table III for six patients with cystic fibrosis from whom regular sputum samples were available.

Table II. Number of isolates of each biotype in cystic fibrosis patients for corresponding 3month periods of 1984 and 1985

\begin{tabular}{|c|c|c|c|c|c|c|}
\hline \multirow[b]{2}{*}{ Biotype } & \multicolumn{3}{|c|}{$\begin{array}{l}\text { Number }(\%) \text { of isolates } \\
\text { in } 1984 \text { from }\end{array}$} & \multicolumn{3}{|c|}{$\begin{array}{c}\text { Number }(\%) \text { of isolates } \\
\text { in } 1985 \text { from }\end{array}$} \\
\hline & AMJ & JAS & OND & AMJ & JAS & OND \\
\hline I & $11(20 \cdot 3)$ & $16(27 \cdot 5)$ & $4(14 \cdot 8)$ & $5(11 \cdot 6)$ & $8(18 \cdot 1)$ & $17(23.9)$ \\
\hline II & $19(35 \cdot 1)$ & $16(27.5)$ & $4(14 \cdot 8)$ & $7(16 \cdot 2)$ & $7(15.9)$ & $15(21 \cdot 1)$ \\
\hline III & $10(18.5)$ & $8(13.7)$ & $4(14 \cdot 8)$ & $20(46 \cdot 5)$ & $15(34)$ & $14(19 \cdot 7)$ \\
\hline IV & $5(9 \cdot 2)$ & $7(12)$ & $5(18 \cdot 5)$ & $0(0)$ & $5(11 \cdot 3)$ & $4(5 \cdot 6)$ \\
\hline V & $7(12 \cdot 9)$ & $8(13 \cdot 7)$ & $3(11 \cdot 1)$ & $2(4 \cdot 6)$ & $3(6 \cdot 8)$ & $16(22 \cdot 5)$ \\
\hline VI & $1(1.8)$ & $1(1 \cdot 7)$ & $2(7 \cdot 4)$ & $3(6.9)$ & $2(4 \cdot 5)$ & $2(2 \cdot 8)$ \\
\hline VII & $0(0)$ & $1(1.7)$ & $1(3 \cdot 7)$ & $2(4 \cdot 6)$ & $1(2 \cdot 2)$ & $1(1.4)$ \\
\hline VIII & $1(1 \cdot 8)$ & $1(1 \cdot 7)$ & $4(14 \cdot 8)$ & $4(9 \cdot 2)$ & $3(6 \cdot 8)$ & $2(2 \cdot 8)$ \\
\hline Total & 54 & 58 & 27 & 43 & 44 & 71 \\
\hline
\end{tabular}


Five of the selected six patients showed a wide spread of biotypes at different times. Only one patient (5), seemed to harbour the same biotype-II strain for more than one year. Few if any other patterns are evident and it appears from these findings that specific biotypes may change rapidly. Table III also shows that two and even three different biotypes were often present in the same sample. These six patients are representative of a larger group of cystic fibrosis patients and were selected because of the large number of samples tested.

Of all cystic fibrosis samples tested, $22 \%$ contained more than one biotype, with a maximum of four in one specimen. This compares with only one patient out of 148 in the respiratory illness group, who had two biotypes simultaneously; none of the 74 in the non-respiratory group had more than one biotype. Selection of only three colonies for testing where the colonial morphology is identical may fail to detect a biotype present in small numbers, but there is nonetheless a clear difference between the cystic fibrosis group and the other two in this respect.

\section{Discussion}

Typing of $H$. influenzae strains is difficult because outer-membrane profiles appear to be too variable and lipopolysaccharide patterns too homogeneous. Most upper respiratory strains are non-capsulate, so serotyping is not possible. Biotyping seems satisfactory and has contributed greatly to classification. Biotypes I and II have mostly been associated with meningitis and septicaemia although geographical differences are apparent. Biotype III, for example, comprised $25 \%$ of blood isolates in New York State (Granato et al., 1983). Similar strains were often seen in Taiwan (Tsai and $\mathrm{Wu}, 1979)$. Biotype-II strains predominated in respiratory specimens in Sweden (Kamme, 1980). DeMaria et al. (1984) also reported biotype-II strains in isolates from $53 \%$ of 33 children with otitis media. We also found most biotype II strains to occur in respiratory infections in patients without cystic fibrosis although similar strains predominated in the respiratory tracts of subjects with no evidence of respiratory infection (Watson et al., 1985). However, in patients with cystic fibrosis, biotype I was much commoner than biotype II. It is not clear why cystic fibrosis patients have different biotypes from those in the general community. Interchange of strains between patients may be a factor, and biotype II strains may have some survival advantage in the respiratory tracts of persons without cystic fibrosis.

We were unable to follow possible changes in biotypes in the respiratory illness and non-respiratory group because only one specimen was examined from any one patient. However, the distributional changes with time in the cystic fibrosis group are of considerable interest. Table III shows how quickly biotypes can change from

Table III. Biotype distribution in 1984-1986 in six patients with cystic fibrosis

\begin{tabular}{|c|c|c|c|c|c|c|c|c|c|c|c|c|c|c|c|c|c|c|c|c|c|c|c|}
\hline \multirow{3}{*}{$\begin{array}{l}\text { Patient } \\
\text { no. }\end{array}$} & \multicolumn{23}{|c|}{ Biotypes isolated in } \\
\hline & \multicolumn{9}{|c|}{1984} & \multicolumn{12}{|c|}{1985} & \multicolumn{2}{|c|}{1986} \\
\hline & A & $\mathbf{M}$ & $\mathbf{J}$ & $\mathbf{J}$ & A & $S$ & o & $\mathbf{N}$ & D & $\mathbf{J}$ & F & $\mathbf{M}$ & A & $\mathbf{M}$ & $\mathbf{J}$ & $\mathbf{J}$ & A & $S$ & O & $\mathbf{N}$ & D & $\mathbf{J}$ & $\mathbf{F}$ \\
\hline 1 & III & & I & I & I & I & & $\begin{array}{l}\text { III } \\
\text { VI }\end{array}$ & VI & I & III & VI & $\begin{array}{l}\text { II } \\
\text { VII }\end{array}$ & III & $\begin{array}{l}\text { II } \\
\text { VI } \\
\text { VII }\end{array}$ & II & $\begin{array}{c}\text { III } \\
\text { V } \\
\text { VIII }\end{array}$ & & & & $\begin{array}{c}\text { V } \\
\text { VIII }\end{array}$ & $\begin{array}{l}\text { V } \\
\text { VI }\end{array}$ & V \\
\hline 2 & & $\begin{array}{l}\text { III } \\
\text { I }\end{array}$ & III & V & I & V & & & IV & IV & & & II & III & III & $\begin{array}{l}\text { III } \\
\text { IV }\end{array}$ & IV & & I & I & IV & IV & I \\
\hline 3 & & & & I & I & I & I & & & IV & II & & & & II & III & & $\begin{array}{l}\text { II } \\
\text { III } \\
\text { IV }\end{array}$ & I & $\begin{array}{c}\text { I } \\
\text { II } \\
\text { III }\end{array}$ & II & $\begin{array}{l}\text { III } \\
\text { IV }\end{array}$ & \\
\hline 4 & & III & V & II & III & V & V & & $\begin{array}{c}\text { III } \\
\text { V } \\
\text { VI }\end{array}$ & & & & VI & $\begin{array}{c}\text { VI } \\
\text { VIII }\end{array}$ & & & VII & $\underset{\text { VIII }}{\text { III }}$ & III & & $\begin{array}{c}\text { III } \\
\text { VIII }\end{array}$ & & \\
\hline 5 & & II & I & II & II & II & II & II & & II & & & II & & & VII & & II & II & & & & \\
\hline 6 & & $\begin{array}{l}\text { V } \\
\text { II }\end{array}$ & IV & IV & IV & $\begin{array}{l}\text { IV } \\
\text { V }\end{array}$ & IV & VI & VI & IV & IV & & & & & III & $\begin{array}{l}\text { III } \\
\text { VII }\end{array}$ & III & III & & & & \\
\hline
\end{tabular}


one month to the next in some patients. We have no evidence to suggest that these changes are associated with antibiotic therapy; they may be largely quantitative, with persistence in small numbers of one type when another becomes dominant.

Not all cystic fibrosis patients showed rapid changes in biotype. Patient no. 5, for example, maintained biotype II for at least one year. This patient's sister, who also had cystic fibrosis, had the same biotype between April and October 1984, suggesting spread within the family. A longitudinal study of normal persons would be required to show whether they also have similar rapid changes in biotypes inhabiting the upper respiratory tract.

The cystic fibrotics differed from the other groups in harbouring more than one biotype simultaneously; four were found in one sample from a cystic fibrosis patient. Since only three colonies of each colonial type were tested, more extensive testing

\section{REFERENCES}

DeMaria T F, Lim D J, Barnishan J, Ayers L W, Birck H G 1984 Biotypes of serologically non-typable Haemophilus influenzae isolated from the middle ears and nasopharynges of patients with otitis media with effusion. Journal of Clinical Microbiology 20 : 1102-1104.

Granato P A, Jurek E A, Weiner L B 1983 Biotypes of Haemophilus influenzae: relationship to clinical source of isolation, serotype and antibiotic susceptibility. American Journal of Clinical Pathology 79 : 73-77.

Gratten M 1983 Haemophilus influenzae biotype VII. Journal of Clinical Microbiology 18: 1015-1016.

Kamme C 1980 Biotypes of capsulated and non-capsulated Haemophilus influenzae. Correlation between biotypes and beta-lactamase production. Acta Pathologica et Microbiologica Scandinavica, Section B 88: 261-264.

Kilian M 1976 A taxonomic study of the genus Haemophilus, might have detected even more patients with multiple biotypes in this group. The factors which influence the host-parasite relationship in cystic fibrosis and allow different strains to co-exist in a way rarely seen in persons without cystic fibrosis are not clear.

Our study found no relationship between colonial morphology and biotype. Different colonial forms were often of the same biotype, whereas similar colonies were often of different biotypes.

The pathogenicity of $H$. influenzae in respiratory infection in children with cystic fibrosis is suspected but not proven. There is at present no evidence that particular biotypes are more likely to be pathogenic than others, although the predominance of biotype I strains in meningitis and septicaemia raises this possibility. Detailed studies are required to determine the relationship, if any, between phenotypic characteristics as expressed in the biotype and pathogenic mechanisms in these infections.

with the proposal of a new species. Journal of General Microbiology 93: 9-62.

Mehtar A, Afshar S A 1983 Biotyping of Haemophilus using API 10S - an epidemiological tool? Journal of Clinical Pathology 36: 96-99.

Sottnek F O, Albritton W L 1984 Haemophilus influenzae biotype VIII. Journal of Clinical Microbiology 20: 815-816.

Tsai W C, Wu J J 1979 Serotypes and biotypes and antibiotic susceptibility of Haemophilus influenzae encountered in a clinical laboratory in Taiwan. Chinese Journal of Microbiology 12 : 140-148.

Watson K C, Kerr E J, Baillie M 1986 Comparison of API-10S and conventional tube tests for biotyping Haemophilus influenzae. Journal of Clinical Pathology 39: 692-693.

Watson K C, Kerr E J C, Hinks C A 1985 The distribution of biotypes of Haemophilus influenzae and $H$. parainfluenzae in patients with cystic fibrosis. Journal of Clinical Pathology 38: $750-753$. 